\title{
Article \\ Impact of Types of Breathing on Static Balance Ability in Healthy Adults
}

\author{
Sung-Hyeon Kim ${ }^{1,+}$, Ho-Jin Shin ${ }^{1,+}$ and Hwi-Young Cho ${ }^{2, *}$ (1) \\ 1 Department of Health Science, Gachon University Graduate School, Incheon 21936, Korea; \\ gpgkorea30@gmail.com (S.-H.K.); gpgkorea89@gmail.com (H.-J.S.) \\ 2 Department of Physical Therapy, College of Health Science, Gachon University, Incheon 21936, Korea \\ * Correspondence: hwiyoung@gachon.ac.kr; Tel.: +82-32-820-4560; Fax: +82-32-820-4449 \\ + These authors contributed equally to this work.
}

check for updates

Citation: Kim, S.-H.; Shin, H.-J.; Cho, H.-Y. Impact of Types of Breathing on Static Balance Ability in Healthy Adults. Int. J. Environ. Res. Public Health 2022, 19, 1205. https:// doi.org/10.3390/ijerph19031205

Academic Editor: José

Carmelo Adsuar Sala

Received: 8 November 2021

Accepted: 20 January 2022

Published: 21 January 2022

Publisher's Note: MDPI stays neutral with regard to jurisdictional claims in published maps and institutional affiliations.

Copyright: (C) 2022 by the authors. Licensee MDPI, Basel, Switzerland. This article is an open access article distributed under the terms and conditions of the Creative Commons Attribution (CC BY) license (https:// creativecommons.org/licenses/by/ $4.0 /)$.

\begin{abstract}
Recent studies have suggested that breathing type may affect balance ability. However most of these studies were conducted on the elderly and patients with musculoskeletal or neurological disorders. Therefore, the effect of voluntary breathing, such as thoracic and abdominal breathing, on the balance ability of people in various age groups is not clearly understood. The purpose of this study was to investigate the differences in balance ability according to the type of breathing in healthy young adults. This study included 78 healthy, young adults. All subjects were assessed for balance ability in neutral breathing, thoracic breathing, and abdominal breathing through a crossover design. Balance ability was assessed during static standing using a force plate. Participants were trained in voluntary breathing, evaluated using electromyography. During voluntary breathing, sway velocity, anterior-posterior difference, and anterior-posterior standard deviation increased while anterior-posterior sample entropy decreased compared to neutral breathing $(p<0.05)$. Compared with thoracic breathing, abdominal breathing increased sway velocity and variability, and reduced complexity $(p<0.05)$. These findings show that balance ability is affected by breathing, even in healthy young adults.
\end{abstract}

Keywords: healthy volunteers; breathing; balance ability

\section{Introduction}

Balance is the ability to maintain the center of gravity (COG) in the base of support (BOS) with minimum postural sway [1-5]. Balance ability is essential to perform all the movements required for activities of daily living. Sitting, standing, two-legged and onelegged standing, and gait are the most basic and functional movements in daily life based on balance function. Deterioration of body functions due to aging and diseases could adversely affect balance functions, such as a decrease in the ability to maintain COG in the BOS and an increase in the sway area in response to postural changes [3-5]. Furthermore, this decrease in balance ability can lead to a decrease in the range of daily life and an increase in the fall accident rate [6].

To maintain balance, the ability to perceive the body through various sensory organs is required [7]. The visual system provides sensory information to maintain balance and perception of position and direction in space [8]. The somatosensory system provides sensory information through joint receptors, muscle spindles, Golgi tendon organs, and cutaneous receptors. The vestibular system provides information about the position of the head and receives movement information related to gravity and inertial forces. Information about body position is transmitted to the central nervous system, which transmits signals to the muscular system to maintain balance. The muscular system maintains the human body's equilibrium by controlling posture through signals from the central nervous system $[9,10]$. As such, the maintenance and control of balance are required for the complex coordination 
of the sensory system, central nervous system, and muscular system as well as coordination with other physical factors.

In order to accurately evaluate balance ability, a previous study has suggested that the environment between measurements or between subjects be controlled, and generally recommend adjusting the ground and the subject's measurement posture [11]. In addition to these standardized evaluation methods, some studies have recently reported that breathing can also affect balance ability $[12,13]$. Voluntary breathing can activate the cerebral cortex and, along with it, can affect muscle control in the lower extremities and upper extremities [12]. Hernandez et al. [12] suggested that the degree of synchronization of breathing and postural sway is high in the elderly, and therefore voluntary breathing has a great influence on the maintenance and control of balance. Alain et al. [13] suggested that thoracic movements have a longer lever arm than abdominal movements, and thoracic breathing (TB) may induce greater sway than abdominal breathing $(\mathrm{AB})$ because it induces activation of peripheral muscles around the cervical spine.

Balance ability is most commonly considered to evaluate the motor function, daily life movements, gait, and sports performance in various subjects [14], and understanding of balance ability is essential to accurately perform it. The maintenance and control of balance could be affected not only by visual, vestibular senses, and proprioception, but also by breathing and other factors, but there are very few studies that clearly investigate this. In addition, most of the studies that have studied balance to date have been conducted in the elderly and patients who are highly affected by variables related to breathing. For this reason, the effects of breathing methods on different age groups and healthy people are not clear. The purpose of this study was to investigate the differences in balance ability according to the type of breathing in healthy young adults.

\section{Materials and Methods}

\subsection{Participants}

Participants in this study were recruited through bulletin board advertisements and posters in community service centers and G university in I city. Participants were recruited for sedentary residents who did not a vigorous-intensity physical activity for 3 or more days per week, for 30 or more minutes [12,15]. The exclusion criteria were as follows: (1) smokers and those with abnormal lung function; (2) neurological or musculoskeletal disorders; and (3) inability to maintain a one-legged standing position for more than 20 s. A total of 94 volunteers expressed their intention to participate in the study, and 78 healthy young adults (mean age: 22.54 years) who met the study participation criteria were enrolled. All participants signed the research consent form after a detailed explanation of the study process, benefits, and risks of side effects. This study was approved by the Institutional Review Board of Gachon University (IRB number: 1044396-202101-HR-003-01) and was registered in a clinical research information service that complies with the World Health Organization International Clinical Trials Registry Platform (registration number: KCT0006026).

The sample size was calculated using G-power software (version 3.1.9.4, Heinrich Heine University, Dusseldorf, Germany) $[16,17]$. Based on the study results of Hernandez et al. [12], the effect size $\mathrm{f}$ was set to 0.246 , the alpha level was set to 0.05 , and the power was set to 0.8 . Consequently, a sample size of 29 was required. Considering a dropout rate of $20 \%$, a total of 37 participants were required.

\subsection{Study Design}

This study followed a randomized crossover design. A CONSORT flow diagram with a crossover design is shown in Figure 1. This study evaluated balance ability in three breathing conditions (neutral breathing $[\mathrm{NB}], \mathrm{TB}$, and $\mathrm{AB}$ ). After baseline (NB) measurements, 78 subjects were randomized to the TB group or AB group using a permuted-block randomization method. Participants received breathing training corresponding to each group. Balance ability was assessed using the trained breathing technique. After a one-week 
washout period, all participants were trained in the rest of the breathing methods, and their balance ability was assessed using the trained breathing methods. All breathing training was performed by a physical therapist with more than 5 years of clinical experience, and all measurements were conducted by a researcher with more than 5 years of clinical experience and a master's degree or higher under a blinded condition about group assignment and the intervention.

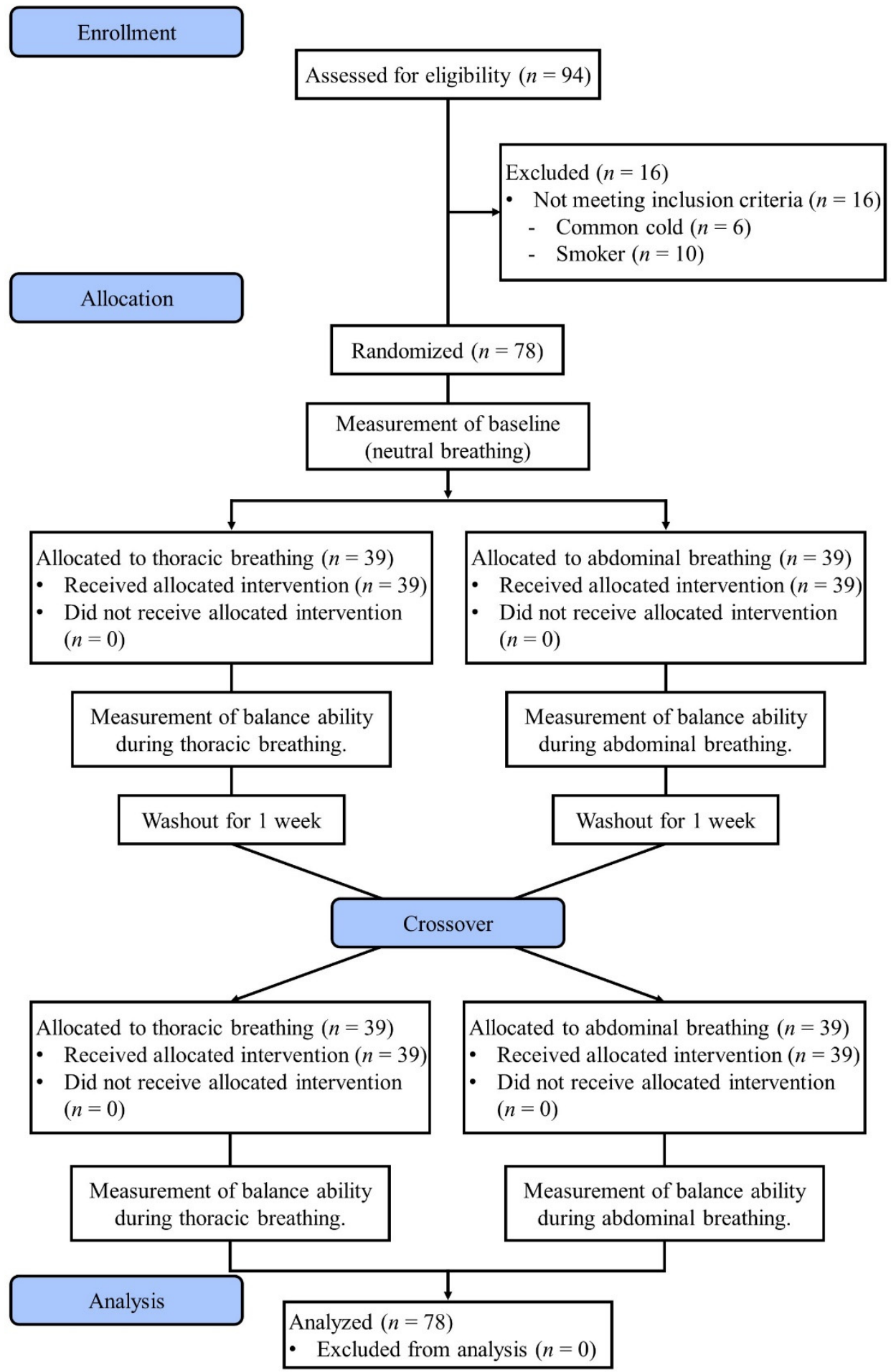

Figure 1. A CONSORT flow diagram with crossover design. 


\subsection{Intervention}

Training for voluntary breathing, that is $\mathrm{TB}$ and $\mathrm{AB}$, was undertaken using real-time feedback from electromyogram (EMG) signals. During TB training, participants were instructed to: "Breathe to move the upper graph (external intercostal muscle activity) and keep the lower graph (transverse abdominal muscle activity) as flat as possible.". Similarly, during AB training, participants were instructed to: "Breathe to move the lower graph (transverse abdominal muscle activity) and keep the upper graph (external intercostal muscle activity) as flat as possible." Respiratory muscles consistent with the breathing type were to be maintained at higher activity than during NB. The rest of the muscles were to be maintained at a flat line with an activity that did not exceed the mean \pm 2 standard deviations (SDs) of NB activity. After voluntary breathing training, participants were asked to undertake breathing training for 1 week. After 1 week, voluntary breathing activity was assessed and balance ability was measured.

\subsection{Assessment}

\subsubsection{Balance Ability}

Balance ability was measured with AccuSway (Advanced Mechanical Technology, Inc., Watertown, MA, USA), which showed high reliability (ICC for inter-rater and test-retest reliability $=0.70-0.89$ ) [18]. All outcome variables were processed with Balance Clinic (AMTI, Watertown, MA, USA) and MATLAB (MathWorks, Natick, MA, USA, version $\mathrm{R} 2020 \mathrm{~b}$ ) based on the displacement of the center of pressure. The sampling frequency was set to $200 \mathrm{~Hz}$, and a 'fourth-order Butterworth' low-pass filter with a cut-off frequency of $10 \mathrm{~Hz}$ was used. All subjects were assessed on their balance ability in the following environments [11]: (1) staring at a X-shaped target located at eye level at a distance of $1.5 \mathrm{~m}$, (2) tips of the toes $30^{\circ}$ apart with a distance of $9 \mathrm{~cm}$ between the heels; and (3) both hands crossed over the shoulder (Figure 2). For measurement of NB, no specific breathing-related instructions other than the measurement position were provided to avoid focusing on the breathing. During voluntary breathing measurement, participants were instructed to maintain their trained breathing techniques. Balance ability was evaluated in both onelegged and two-legged standing, and each test was repeated three times. Each measurement was performed for $20 \mathrm{~s}$, with a 2-min rest period between the trials. In order to exclude the postural perturbation that occurs immediately after taking up a posture from the data, the middle $10 \mathrm{~s}$ of data out of a total of $20 \mathrm{~s}$ of measurement were used for analysis. The measured balance variables are shown in Table 1 .

Table 1. Balance ability parameters.

\begin{tabular}{|c|c|}
\hline Variables & Definition \\
\hline Sway Area & The area of COP displacement per unit time. \\
\hline Sway Velocity & $\begin{array}{c}\text { The movement speed of the COP displacement per } \\
\text { unit time. }\end{array}$ \\
\hline Anterior-Posterior difference & $\begin{array}{l}\text { The maximum distance in the anterior-posterior } \\
\text { direction of the COP displacement. }\end{array}$ \\
\hline Right-Left difference & $\begin{array}{l}\text { The maximum distance in the left-right direction of } \\
\text { the COP displacement. }\end{array}$ \\
\hline Anterior-Posterior standard deviation & $\begin{array}{l}\text { The variability in the anterior-posterior direction of } \\
\text { the COP displacement. }\end{array}$ \\
\hline Right-Left standard deviation & $\begin{array}{c}\text { The variability in the left-right direction of the COP } \\
\text { displacement. }\end{array}$ \\
\hline Anterior-Posterior sample entropy & $\begin{array}{l}\text { The complexity in the anterior-posterior direction of } \\
\text { the COP displacement. }\end{array}$ \\
\hline Right-Left sample entropy & $\begin{array}{c}\text { The complexity in the left-right direction of the COP } \\
\text { displacement. }\end{array}$ \\
\hline
\end{tabular}



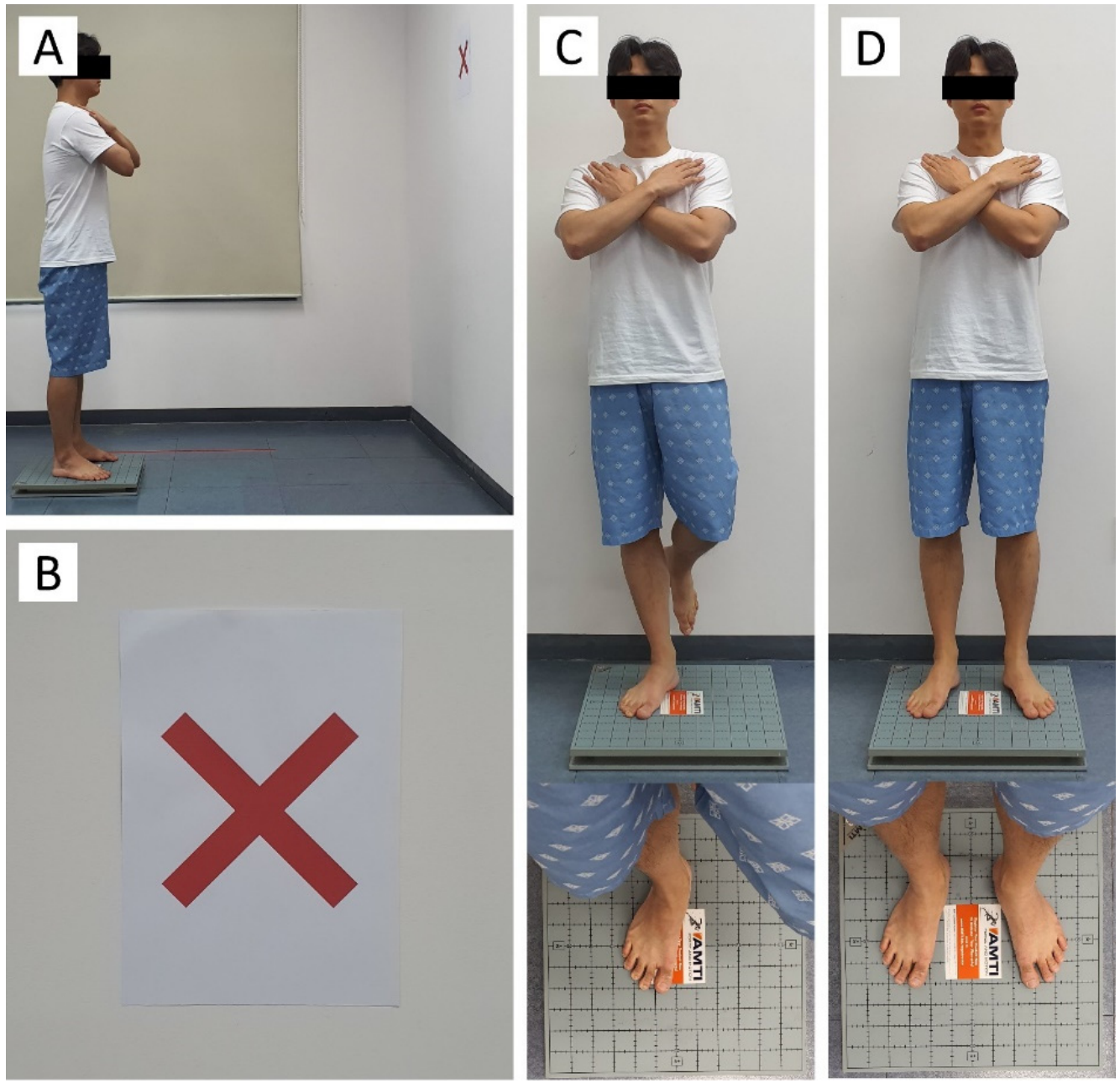

Figure 2. Static balance measurement. (A), Balance measuring environment. (B), X-shaped target. (C), One-legged standing posture. (D), Two-legged standing posture.

\subsubsection{Muscle Activity}

Real-time feedback via EMG signals was used to evaluate voluntary breathing during breathing training and measurements. EMG signals were collected with AcqKnowledge 5.0 (BIOPAC systems, Goleta, CA, USA). The band-pass filter was set to 30-500, and the sampling rate was set to $1000 \mathrm{~Hz}$. The EMG signal was full-wave rectified. Electrodes were attached to the external intercostal muscles (between the 6th and 7th ribs), sternocleidomastoid muscle ( $1 / 3$ of the distance between the mastoid process and the jugular notch), transverse abdominis muscle ( $3 \mathrm{~cm}$ lateral to the center of the navel), and rectus abdominis muscle ( $2 \mathrm{~cm}$ below the anterior superior iliac spine) after hair removal and exfoliation with alcohol $[19,20]$.

\subsection{Statistical Analysis}

For all variables, the average value of the data was repeated three times and expressed as the mean \pm SD. Statistical analysis was performed using SPSS statistical software (version 25.0; SPSS Inc., Chicago, IL, USA). The Kolmogorov-Smirnov test was used to assess normal distribution, and non-parametric statistical methods were used for non-normal variables. Balance ability with each breathing technique was compared using the Friedman test followed by the Wilcoxon signed-rank test, and the significance level was corrected using the Bonferroni correction method. The critical value of significance was set at $\alpha=0.05$. 


\section{Results}

\subsection{General Characteristics of Participants}

The 78 subjects who participated in this study completed all the interventions and evaluations; there were no dropouts. The general characteristics of the participants are presented in Table 2.

Table 2. General characteristics of participants.

\begin{tabular}{|c|c|}
\hline Variables & Participants $(n=78)$ \\
\hline Sex $($ female $/$ male $) *$ & $38 / 40$ \\
\hline Age (years) ${ }^{\dagger}$ & $22.54 \pm 2.69$ \\
\hline Height $(\mathrm{cm})^{\dagger}$ & $169.68 \pm 8.43$ \\
\hline Weight $(\mathrm{kg})^{\dagger}$ & $63.82 \pm 12.47$ \\
\hline Body mass index $\left(\mathrm{kg} / \mathrm{m}^{2}\right)^{+}$ & $22.01 \pm 2.89$ \\
\hline Leg length $(\mathrm{cm})^{\dagger}$ & $85.99 \pm 4.73$ \\
\hline
\end{tabular}

* Values are expressed as number $(\mathrm{N}){ }^{\dagger}{ }^{\dagger}$ Values are expressed as mean $\pm \mathrm{SD}$.

\subsection{Electromyogram}

Table 3 shows respiratory muscle activity during double-leg stance and single-leg stance. The external intercostals and sternocleidomastoid were significantly more active in $\mathrm{TB}$ while the transverse abdominis and rectus abdominis were significantly more active in $\mathrm{AB}$.

Table 3. Muscle activity according to the type of breathing.

\begin{tabular}{|c|c|c|c|c|c|}
\hline Electromyography & BL & $\begin{array}{c}\text { NB } \\
\mathbf{M} \pm \mathrm{SD}\end{array}$ & $\begin{array}{c}\text { TB } \\
\mathrm{M} \pm \mathrm{SD}\end{array}$ & $\begin{array}{c}\mathrm{AB} \\
\mathrm{M} \pm \mathrm{SD}\end{array}$ & $p$-Value \\
\hline \multicolumn{6}{|l|}{ Double-leg stance $(\mathrm{uV})$} \\
\hline External intercostals & 5.90 & $3.70 \pm 1.38$ & $6.91 \pm 2.81^{* * *}$ & $5.04 \pm 0.46^{* * \dagger}$ & $<0.001$ \\
\hline Sternocleidomastoid & 4.81 & $3.55 \pm 1.33$ & $7.01 \pm 1.73^{* * *}$ & $3.13 \pm 1.59^{++t}$ & $<0.001$ \\
\hline Transverse abdominis & 16.06 & $10.34 \pm 2.80$ & $15.71 \pm 4.14^{* *}$ & $21.66 \pm 1.22 * * *+++$ & $<0.001$ \\
\hline Rectus abdominis & 3.31 & $2.27 \pm 0.49$ & $2.32 \pm 0.44$ & $5.48 \pm 1.30^{* * *++\dagger}$ & $<0.001$ \\
\hline \multicolumn{6}{|l|}{ Single-leg stance (uV) } \\
\hline External intercostals & 7.55 & $4.86 \pm 1.62$ & $8.24 \pm 1.58^{* * *}$ & $5.39 \pm 1.33$ *t+† & $<0.001$ \\
\hline Sternocleidomastoid & 5.03 & $4.49 \pm 0.23$ & $5.30 \pm 0.32^{* * *}$ & $4.82 \pm 0.43$ & $<0.001$ \\
\hline Transverse abdominis & 23.88 & $17.17 \pm 4.55$ & $20.09 \pm 6.28 *$ & $26.40 \pm 5.79 * * *++$ & $<0.001$ \\
\hline Rectus abdominis & 5.03 & $4.41 \pm 2.56$ & $4.12 \pm 1.94$ & $9.82 \pm 1.98^{* * *++\dagger}$ & $<0.001$ \\
\hline
\end{tabular}

Note: $\mathrm{M}$, mean; $\mathrm{SD}$, standard deviation; $\mathrm{BL}$, baseline; $\mathrm{NB}$, neutral breathing; $\mathrm{TB}$, thoracic breathing; $\mathrm{AB}$, abdominal breathing; ${ }^{*} p<0.05,{ }^{* *} p<0.01,{ }^{* * *} p<0.001$, vs. NB; ${ }^{\dagger} p<0.05,{ }^{+\dagger} p<0.01,{ }^{++\dagger} p<0.001$, vs. TB.

\subsection{Balance Ability}

3.3.1. Balance Ability in Double-Leg Stance

The balance ability results for standing on both feet are presented in Table 4 . The sway velocity and anterior-posterior difference were significantly smaller in NB than in TB and $\mathrm{AB}(p<0.05)$. The anterior-posterior standard deviation was lowest in NB and highest in $\mathrm{AB}(p<0.05)$. The anterior-posterior sample entropy was highest in NB and lowest in AB $(p<0.05)$. There was no significant difference between conditions in sway area, right-left difference, right-left standard deviation, and right-left sample entropy. 
Table 4. Balance ability in double-leg stance.

\begin{tabular}{|c|c|c|c|c|c|c|c|c|c|c|}
\hline \multirow[b]{2}{*}{ Variable } & \multicolumn{2}{|c|}{ NB } & \multicolumn{2}{|c|}{ TB } & \multicolumn{2}{|c|}{ AB } & \multirow[t]{2}{*}{ Total- $p$} & \multicolumn{3}{|c|}{ Post-Hoc Test } \\
\hline & $\begin{array}{c}\text { Mean } \pm \\
\text { SD }\end{array}$ & $\begin{array}{c}\text { Median } \\
\text { (IQR) }\end{array}$ & $\begin{array}{c}\text { Mean } \pm \\
\text { SD }\end{array}$ & $\begin{array}{c}\text { Median } \\
\text { (IQR) }\end{array}$ & $\begin{array}{c}\text { Mean } \pm \\
\text { SD }\end{array}$ & $\begin{array}{c}\text { Median } \\
\text { (IQR) }\end{array}$ & & $\begin{array}{c}\text { NB vs. } \\
\text { TB }\end{array}$ & $\begin{array}{c}\text { NB vs. } \\
\text { AB }\end{array}$ & $\begin{array}{c}\text { TB vs. } \\
\text { AB }\end{array}$ \\
\hline $\mathrm{SA}\left(\mathrm{cm}^{2}\right)$ & $\begin{array}{c}1.19 \pm \\
0.81\end{array}$ & $\begin{array}{c}1.01 \\
(0.88)\end{array}$ & $\begin{array}{c}1.24 \pm \\
0.80\end{array}$ & $\begin{array}{c}1.13 \\
(0.78)\end{array}$ & $\begin{array}{c}1.36 \pm \\
1.01\end{array}$ & $\begin{array}{c}1.12 \\
(0.96)\end{array}$ & 0.174 & 1.000 & 0.072 & 0.327 \\
\hline $\begin{array}{c}\mathrm{SV} \\
(\mathrm{cm} / \mathrm{s})\end{array}$ & $\begin{array}{c}1.51 \pm \\
0.66\end{array}$ & $\begin{array}{c}1.36 \\
(1.19)\end{array}$ & $\begin{array}{c}1.59 \pm \\
0.65\end{array}$ & $\begin{array}{c}1.48 \\
(1.06)\end{array}$ & $\begin{array}{c}1.63 \pm \\
0.68\end{array}$ & $\begin{array}{c}1.57 \\
(1.08)\end{array}$ & $<0.001$ & 0.010 & $<0.001$ & 0.061 \\
\hline $\begin{array}{l}\text { RL-Diff } \\
(\mathrm{cm})\end{array}$ & $\begin{array}{c}0.96 \pm \\
0.58\end{array}$ & $\begin{array}{c}0.89 \\
(0.73)\end{array}$ & $\begin{array}{c}0.92 \pm \\
0.56\end{array}$ & $\begin{array}{c}0.81 \\
(0.58)\end{array}$ & $\begin{array}{c}0.95 \pm \\
0.63\end{array}$ & $\begin{array}{c}0.80 \\
(0.58)\end{array}$ & 0.905 & 1.000 & 1.000 & 1.000 \\
\hline $\begin{array}{l}\text { AP-Diff } \\
(\mathrm{cm})\end{array}$ & $\begin{array}{c}2.01 \pm \\
1.29\end{array}$ & $\begin{array}{c}1.57 \\
(1.73)\end{array}$ & $\begin{array}{c}2.28 \pm \\
1.35\end{array}$ & $\begin{array}{c}1.95 \\
(1.63)\end{array}$ & $\begin{array}{c}2.34 \pm \\
1.38\end{array}$ & $\begin{array}{c}2.24 \\
(1.62)\end{array}$ & $<0.001$ & $<0.001$ & $<0.001$ & 0.869 \\
\hline RL-SD & $\begin{array}{c}0.180 \pm \\
0.093\end{array}$ & $\begin{array}{c}0.159 \\
(0.125)\end{array}$ & $\begin{array}{c}0.181 \pm \\
0.089\end{array}$ & $\begin{array}{c}0.162 \\
(0.084)\end{array}$ & $\begin{array}{c}0.180 \pm \\
0.096\end{array}$ & $\begin{array}{c}0.153 \\
(0.112)\end{array}$ & 0.752 & 1.000 & 1.000 & 1.000 \\
\hline AP-SD & $\begin{array}{c}0.221 \pm \\
0.115\end{array}$ & $\begin{array}{c}0.218 \\
(0.138)\end{array}$ & $\begin{array}{c}0.320 \pm \\
0.182\end{array}$ & $\begin{array}{c}0.306 \\
(0.224)\end{array}$ & $\begin{array}{c}0.357 \pm \\
0.187\end{array}$ & $\begin{array}{c}0.337 \\
(0.234)\end{array}$ & $<0.001$ & $<0.001$ & $<0.001$ & 0.008 \\
\hline RL-SE & $\begin{array}{c}0.088 \pm \\
0.037\end{array}$ & $\begin{array}{c}0.082 \\
(0.038)\end{array}$ & $\begin{array}{c}0.091 \pm \\
0.035\end{array}$ & $\begin{array}{c}0.087 \\
(0.042)\end{array}$ & $\begin{array}{c}0.086 \pm \\
0.028\end{array}$ & $\begin{array}{c}0.082 \\
(0.037)\end{array}$ & 0.746 & 0.825 & 1.000 & 0.991 \\
\hline AP-SE & $\begin{array}{c}0.079 \pm \\
0.038\end{array}$ & $\begin{array}{c}0.073 \\
(0.049)\end{array}$ & $\begin{array}{c}0.063 \pm \\
0.033\end{array}$ & $\begin{array}{c}0.055 \\
(0.034)\end{array}$ & $\begin{array}{c}0.057 \pm \\
0.028\end{array}$ & $\begin{array}{c}0.050 \\
(0.035)\end{array}$ & $<0.001$ & $<0.001$ & $<0.001$ & 0.033 \\
\hline
\end{tabular}

$\mathrm{NB}$, neutral breathing; $\mathrm{TB}$, thoracic breathing; $\mathrm{AB}$, abdominal breathing; $\mathrm{SD}$, standard deviation; IQR, interquartile range; SA, sway area; SV, sway velocity; RL, right-left; $\mathrm{AP}$, anterior-posterior; Diff, difference; $\mathrm{SE}$, sample entropy.

\subsubsection{Balance Ability in Single-Leg Stance}

The results of the balance ability on one foot are shown in Table 5 . Sway velocity was significantly lower in NB than in $\mathrm{TB}$ or $\mathrm{AB}(p<0.05)$. The anterior-posterior difference was significantly smaller in NB than in $\mathrm{TB}$ or $\mathrm{AB}(p<0.05)$. The right-left standard deviation was significantly smaller in $\mathrm{NB}$ than in $\mathrm{TB}$ or $\mathrm{AB}(p<0.05)$. The anterior-posterior standard deviation was lowest in NB and highest in $\mathrm{AB}(p<0.05)$. The entropy of the right-left sample was significantly higher in NB than in $\mathrm{TB}$ or $\mathrm{AB}(p<0.05)$. The anterior-posterior sample entropy was highest in NB and lowest in $\mathrm{AB}(p<0.05)$. There was no significant difference between the sway area and the right-left difference between the conditions.

Table 5. Balance ability in single-leg stance.

\begin{tabular}{|c|c|c|c|c|c|c|c|c|c|c|}
\hline \multirow[b]{2}{*}{ Variable } & \multicolumn{2}{|c|}{ NB } & \multicolumn{2}{|c|}{ TB } & \multicolumn{2}{|c|}{$\mathbf{A B}$} & \multirow[t]{2}{*}{ Total- $p$} & \multicolumn{3}{|c|}{ Post-Hoc Test } \\
\hline & $\begin{array}{c}\text { Mean } \pm \\
\text { SD }\end{array}$ & $\begin{array}{l}\text { Median } \\
\text { (IQR) }\end{array}$ & $\begin{array}{c}\text { Mean } \pm \\
\text { SD }\end{array}$ & $\begin{array}{l}\text { Median } \\
\text { (IQR) }\end{array}$ & $\begin{array}{c}\text { Mean } \pm \\
\text { SD }\end{array}$ & $\begin{array}{c}\text { Median } \\
\text { (IQR) }\end{array}$ & & $\begin{array}{c}\text { NB vs. } \\
\text { TB }\end{array}$ & $\begin{array}{c}\text { NB vs. } \\
\text { AB }\end{array}$ & $\begin{array}{c}\text { TB vs. } \\
\text { AB }\end{array}$ \\
\hline $\mathrm{SA}\left(\mathrm{cm}^{2}\right)$ & $\begin{array}{c}9.52 \pm \\
3.61\end{array}$ & $\begin{array}{c}8.94 \\
(4.80)\end{array}$ & $\begin{array}{c}9.66 \pm \\
3.55\end{array}$ & $\begin{array}{c}9.02 \\
(3.88)\end{array}$ & $\begin{array}{c}9.26 \pm \\
4.23\end{array}$ & $\begin{array}{c}8.25 \\
(3.02)\end{array}$ & 0.304 & 1.000 & 1.000 & 0.352 \\
\hline $\begin{array}{c}\mathrm{SV} \\
(\mathrm{cm} / \mathrm{s})\end{array}$ & $\begin{array}{c}4.72 \pm \\
0.86\end{array}$ & $\begin{array}{c}4.62 \\
(1.04)\end{array}$ & $\begin{array}{c}5.34 \pm \\
1.00\end{array}$ & $\begin{array}{c}5.07 \\
(1.16)\end{array}$ & $\begin{array}{c}5.28 \pm \\
0.94\end{array}$ & $\begin{array}{c}4.96 \\
(1.33)\end{array}$ & $<0.001$ & $<0.001$ & 0.004 & 0.534 \\
\hline $\begin{array}{l}\text { RL-Diff } \\
(\mathrm{cm})\end{array}$ & $\begin{array}{c}3.33 \pm \\
0.80\end{array}$ & $\begin{array}{c}3.25 \\
(1.10)\end{array}$ & $\begin{array}{c}3.21 \pm \\
0.82\end{array}$ & $\begin{array}{c}3.00 \\
(0.93)\end{array}$ & $\begin{array}{c}3.07 \pm \\
0.81\end{array}$ & $\begin{array}{c}2.78 \\
(0.97)\end{array}$ & 0.477 & 1.000 & 0.249 & 0.273 \\
\hline $\begin{array}{l}\text { AP-Diff } \\
(\mathrm{cm})\end{array}$ & $\begin{array}{c}9.59 \pm \\
2.62\end{array}$ & $\begin{array}{l}10.52 \\
(1.17)\end{array}$ & $\begin{array}{c}10.23 \pm \\
2.65\end{array}$ & $\begin{array}{l}11.25 \\
(1.31)\end{array}$ & $\begin{array}{c}10.08 \pm \\
2.62\end{array}$ & $\begin{array}{l}11.06 \\
(1.00)\end{array}$ & $<0.001$ & $<0.001$ & $<0.001$ & 0.096 \\
\hline RL-SD & $\begin{array}{c}0.566 \pm \\
0.136\end{array}$ & $\begin{array}{c}0.565 \\
(0.168)\end{array}$ & $\begin{array}{c}0.624 \pm \\
0.169\end{array}$ & $\begin{array}{c}0.571 \\
(0.170)\end{array}$ & $\begin{array}{c}0.627 \pm \\
0.162\end{array}$ & $\begin{array}{c}0.590 \\
(0.175)\end{array}$ & 0.001 & 0.035 & 0.002 & 1.000 \\
\hline AP-SD & $\begin{array}{c}0.605 \pm \\
0.173\end{array}$ & $\begin{array}{c}0.550 \\
(0.208)\end{array}$ & $\begin{array}{c}0.643 \pm \\
0.164\end{array}$ & $\begin{array}{c}0.636 \\
(0.217)\end{array}$ & $\begin{array}{c}0.692 \pm \\
0.209\end{array}$ & $\begin{array}{c}0.616 \\
(0.183)\end{array}$ & $<0.001$ & $<0.001$ & $<0.001$ & 0.011 \\
\hline RL-SE & $\begin{array}{c}0.093 \pm \\
0.039\end{array}$ & $\begin{array}{c}0.086 \\
(0.042)\end{array}$ & $\begin{array}{c}0.075 \pm \\
0.033\end{array}$ & $\begin{array}{c}0.072 \\
(0.046)\end{array}$ & $\begin{array}{c}0.075 \pm \\
0.026\end{array}$ & $\begin{array}{c}0.073 \\
(0.031)\end{array}$ & $<0.001$ & $<0.001$ & $<0.001$ & 1.000 \\
\hline AP-SE & $\begin{array}{c}0.108 \pm \\
0.064\end{array}$ & $\begin{array}{c}0.090 \\
(0.038)\end{array}$ & $\begin{array}{c}0.080 \pm \\
0.031\end{array}$ & $\begin{array}{c}0.074 \\
(0.032)\end{array}$ & $\begin{array}{c}0.071 \pm \\
0.026\end{array}$ & $\begin{array}{c}0.073 \\
(0.035)\end{array}$ & $<0.001$ & $<0.001$ & $<0.001$ & 0.002 \\
\hline
\end{tabular}




\section{Discussion}

This study investigated the effect of voluntary breathing on the balance ability of healthy, young adults. It found that voluntary breathing affects balance ability in twolegged and one-legged standing in healthy, young adults and that $\mathrm{AB}$ has a greater effect than TB. Some previous studies have suggested that voluntary breathing can affect the balance ability of the elderly and patients, and our study also confirmed the same tendency in young adults. These results suggest that voluntary breathing may affect balance ability during static standing in the elderly and patients as well as young healthy adults, and it should be controlled to properly perform balance measurements.

Manor et al. [21] defined the phenomenon of postural sway induced by breathing as 'posturo-respiratory synchronization'. Also, he suggested that the elderly or patients with physical disorders had a high degree of synchronization between breathing and posture so that postural sway during static standing would be greatly affected by breathing. Our results showed that sway velocity and anterior-posterior standard deviation increased, and sample entropy decreased during voluntary breathing. These results suggest that healthy, young adults may also be affected by posturo-respiratory synchronization. To maintain postural balance, an ankle strategy is used when slow and low-amplitude perturbations occur, and a hip strategy is used when fast and large amplitude perturbations occur [22]. Hernandez et al. [12] suggested that elderly patients with low back pain who have difficulty in tolerating internal perturbation caused by breath could maintain postural balance by using the hip joint strategy in addition to the ankle strategy. The present study found an increase in postural sway in the forward-backward direction, similar to that in the previous study during one-legged standing in healthy, young adults. These results show that voluntary breathing could affect the equilibrium state of healthy adults and that in challenging situations, an increase in postural sway could occur in healthy young adults, similar to that in the elderly and patients with physical disorders.

When postural perturbation occurs, in addition to using a balance strategy to maintain postural stabilization, anticipatory postural adjustments (APA) could minimize the effects of postural perturbation [23]. Additionally, in the case of large postural perturbations that cannot be offset, balance is maintained through compensatory movements [24,25]. A previous study [12] suggested that postural perturbation by respiratory-induced motion was negligible or absent in healthy young adults, whereas individuals with reduced APA, such as the elderly and patients with low back pain, could be affected. However, our results showed that sway velocity and distance in healthy adults increased during voluntary breathing, and that sway variability and irregularity were also affected. These results can be explained by the differences in the mechanisms of neutral and voluntary breathing. Unlike NB controlled by the brainstem, voluntary breathing involves the activation of the cerebral cortex [26]. The change in the activity of the motor area by voluntary breathing can affect the movement of the trunk and extremities [27]. These effects can interfere with the APA ability to maintain balance, even in healthy young adults.

An increase in respiratory muscle activity during voluntary breathing may affect the increase in sway. Voluntary breathing induces greater activation of respiratory muscles than in NB condition, and our results also showed that the activity of external intercostal muscle and sternocleidomastoid muscle was higher in TB than in NB (Table 3). Furthermore, during $\mathrm{AB}$, the activity of the transverse abdominis and rectus abdominis muscles was higher than that under NB condition. To control trunk volume during voluntary breathing, the thoracic respiratory muscles generate movements of the rib cage in the anterior-posterior, lateral, and up-down directions $[19,28]$, and the AB muscles generate an anterior-posterior movement of the abdominal region $[20,29]$. These additional movements during voluntary breathing could cause internal perturbations and affect the balance ability. In addition, increased activity of the $\mathrm{AB}$ muscles can generate torque in the sagittal plane of the trunk and pelvis. This torque in the sagittal plane can increase sway by generating flexion and extension movements. Unlike previous studies that reported that TB had a greater effect on 
balance ability than $A B$, our study showing that $A B$ had a greater effect on balance ability is considered to be due to the difference in these breathing mechanisms [13].

Balance ability has been most commonly used to evaluate the motor function of healthy adults, the elderly, athletes, and patients with the disorder in the clinic and various sports environments. In order to perform this evaluation more accurately, a previous study has recommended excluding as much as possible the influence of external factors that may affect postural balance and physical function, and to proceed with the evaluation by adjusting the subject's foot position, arm posture, gaze, and measurement surface [11]. While previous studies have suggested that postural balance ability occurs due to voluntary breathing only in the population with reduced physical function [12,13], this study demonstrated that balance ability could be influenced by voluntary breathing even in healthy young adults. Our findings suggest that the command to control breathing should also be considered for control body conditions for postural balance assessment, even in the elderly, patients with the disorder, and healthy adults.

This study investigated changes in the balance ability of healthy, young adults during different breathing methods. However, our study has several limitations. First, the sample size was small; therefore, it is difficult to generalize the results. Second, we did not measure the subject's foot size and width. Therefore, it is difficult to confirm the influence of individual differences according to foot size on postural balance changes following voluntary breathing. Third, when measuring muscle activity, the activity of other muscles was not known because the respiratory muscles were mainly measured. Fourth, it was not possible to control the respiration volume equally during the measurements. For this reason, it was not possible to confirm the difference according to the volume of respiration. Finally, we could not measure changes in posture, such as rib cage volume and changes in three-dimensional movements, during breathing. In order to generalize the study results, it is suggested that additional body measurements, evaluation of extremity muscles, and monitoring of respiratory rate and trunk movement should be performed in subsequent studies.

\section{Conclusions}

The results of this study showed that there is a difference in the balance ability of healthy, young adults according to the type of breathing. In particular, it was found that $\mathrm{AB}$ had a greater effect on balance ability than other breathing methods. Therefore, the breathing method should be controlled for balance evaluations.

Author Contributions: S.-H.K.: conceptualization, methodology, formal analysis, project administration, writing — review and editing, visualization, writing-original draft; H.-J.S.: data curation, investigation, methodology, writing-original draft; H.-Y.C.: conceptualization, resources, supervision, validation, writing review and editing. All authors have read and agreed to the published version of the manuscript.

Funding: This research received no external funding.

Institutional Review Board Statement: The study was conducted according to the guidelines of the Declaration of Helsinki, and approved by the Institutional Review Board of Gachon University (IRB number: 1044396-202101-HR-003-01) and was registered in a clinical research information service that complies with the World Health Organization International Clinical Trials Registry Platform (registration number: KCT0006026).

Informed Consent Statement: Informed consent was obtained from all subjects involved in the study.

Data Availability Statement: The data presented in this study are available on request from the corresponding author.

Acknowledgments: We would like to express our sincere gratitude to all reviewers for their contributions.

Conflicts of Interest: The authors declare no conflict of interest. 


\section{References}

1. Shumway-Cook, A.; Horak, F.B. Assessing the influence of sensory interaction of balance. Suggestion from the field. Phys. Ther 1986, 66, 1548-1550. [CrossRef] [PubMed]

2. Nichols, D.S.; Miller, L.; Colby, L.A.; Pease, W.S. Sitting balance: Its relation to function in individuals with hemiparesis. Arch. Phys. Med. Rehabil. 1996, 77, 865-869. [CrossRef]

3. Thapa, P.B.; Gideon, P.; Brockman, K.G.; Fought, R.L.; Ray, W.A. Clinical and biomechanical measures of balance as fall predictors in ambulatory nursing home residents. J. Gerontol. A Biol. Sci. Med. Sci. 1996, 51, M239-M246. [CrossRef] [PubMed]

4. Johansson, J.; Nordström, A.; Gustafson, Y.; Westling, G.; Nordström, P. Increased postural sway during quiet stance as a risk factor for prospective falls in community-dwelling elderly individuals. Age Ageing 2017, 46, 964-970. [CrossRef]

5. Johansson, J.; Jarocka, E.; Westling, G.; Nordström, A.; Nordström, P. Predicting incident falls: Relationship between postural sway and limits of stability in older adults. Hum. Mov. Sci. 2019, 66, 117-123. [CrossRef]

6. Watanabe, T.; Saito, K.; Ishida, K.; Tanabe, S.; Nojima, I. Coordination of plantar flexor muscles during bipedal and unipedal stances in young and elderly adults. Exp. Brain Res. 2018, 236, 1229-1239. [CrossRef]

7. Anacker, S.L.; Di Fabio, R.P. Influence of sensory inputs on standing balance in community-dwelling elders with a recent history of falling. Phys. Ther. 1992, 72, 575-584. [CrossRef]

8. Grace Gaerlan, M.; Alpert, P.T.; Cross, C.; Louis, M.; Kowalski, S. Postural balance in young adults: The role of visual, vestibular and somatosensory systems. J. Am. Acad. Nurse Pract. 2012, 24, 375-381. [CrossRef]

9. Alexander, N.B. Gait disorders in older adults. J. Am. Geriatr. Soc. 1996, 44, 434-451. [CrossRef]

10. Yogev-Seligmann, G.; Hausdorff, J.M.; Giladi, N. The role of executive function and attention in gait. Mov. Disord. 2008, 23, 329-472. [CrossRef]

11. Palazzo, F.; Caronti, A.; Lebone, P.; Proietti, A.; Panzarino, M.; Annino, G. Effects of stimulating surface during static upright posture in the elderly. Somatosens. Mot. Res. 2015, 32, 61-66. [CrossRef] [PubMed]

12. Hernandez, L.; Manning, J.; Zhang, S. Voluntary control of breathing affects center of pressure complexity during static standing in healthy older adults. Gait Posture 2019, 68, 488-493. [CrossRef] [PubMed]

13. Hamaoui, A.; Gonneau, E.; Le Bozec, S. Respiratory disturbance to posture varies according to the respiratory mode. Neurosci. Lett. 2010, 475, 141-144. [CrossRef] [PubMed]

14. Era, P.; Konttinen, N.; Mehto, P.; Saarela, P.; Lyytinen, H. Postural stability and skilled performance-a study on top-level and naive rifle shooters. J. Biomech. 1996, 29, 301-306. [CrossRef]

15. Takazakura, R.; Takahashi, M.; Nitta, N.; Murata, K. Diaphragmatic motion in the sitting and supine positions: Healthy subject study using a vertically open magnetic resonance system. J. Magn. Reson. Imaging 2004, 19, 605-609. [CrossRef]

16. Faul, F.; Erdfelder, E.; Lang, A.G.; Buchner, A. G*Power 3: A flexible statistical power analysis program for the social, behavioral, and biomedical sciences. Behav. Res. Methods 2007, 39, 175-191. [CrossRef]

17. Faul, F.; Erdfelder, E.; Buchner, A.; Lang, A.G. Statistical power analyses using G*Power 3.1: Tests for correlation and regression analyses. Behav. Res. Methods 2009, 41, 1149-1160. [CrossRef]

18. Swanenburg, J.; de Bruin, E.D.; Favero, K.; Uebelhart, D.; Mulder, T. The reliability of postural balance measures in single and dual tasking in elderly fallers and non-fallers. BMC Musculoskelet. Disord. 2008, 9, 162. [CrossRef]

19. Wilson, T.A.; Legrand, A.; Gevenois, P.A.; De Troyer, A. Respiratory effects of the external and internal intercostal muscles in humans. J. Physiol. 2001, 530, 319-330. [CrossRef]

20. Montes, A.M.; Baptista, J.; Crasto, C.; de Melo, C.A.; Santos, R.; Vilas-Boas, J.P. Abdominal muscle activity during breathing with and without inspiratory and expiratory loads in healthy subjects. J. Electromyogr. Kinesiol. 2016, 30, 143-150. [CrossRef]

21. Manor, B.D.; Hu, K.; Peng, C.K.; Lipsitz, L.A.; Novak, V. Posturo-respiratory synchronization: Effects of aging and stroke. Gait Posture 2012, 36, 254-259. [CrossRef] [PubMed]

22. Blenkinsop, G.M.; Pain, M.T.G.; Hiley, M.J. Balance control strategies during perturbed and unperturbed balance in standing and handstand. R. Soc. Open Sci. 2017, 4, 61018. [CrossRef] [PubMed]

23. Aimola, E.; Santello, M.; La Grua, G.; Casabona, A. Anticipatory postural adjustments in reach-to-grasp: Effect of object mass predictability. Neurosci. Lett. 2011, 502, 4-88. [CrossRef] [PubMed]

24. Xie, L.; Wang, J.; Zhang, Z.; Yuan, L.; Wang, C. Psychological predictive effects of sudden posture perturbation. Acta Psychol. Sin. 2014, 46, 958-974. [CrossRef]

25. Xie, L.; Wang, J. Anticipatory and compensatory postural adjustments in response to loading perturbation of unknown magnitude. Exp. Brain Res. 2019, 237, 173-180. [CrossRef] [PubMed]

26. McKay, L.C.; Evans, K.C.; Frackowiak, R.S.; Corfield, D.R. Neural correlates of voluntary breathing in humans. J. Appl. Physiol. 2003, 95, 1170-1178. [CrossRef]

27. Shirakawa, K.; Yunoki, T.; Afroundeh, R.; Lian, C.S.; Matsuura, R.; Ohtsuka, Y.; Yano, T. Voluntary breathing increases corticospinal excitability of lower limb muscle during isometric contraction. Respir. Physiol. Neurobiol. 2015, 217, 40-45. [CrossRef]

28. Donley, E.R.; Holme, M.R.; Loyd, J.W. Anatomy, Thorax, Wall Movements. In StatPearls; StatPearls Publishing: Treasure Island, FL, USA, 2020.

29. Hildenbrand, K.; Noble, L. Abdominal Muscle Activity While Performing Trunk-Flexion Exercises Using the Ab Roller, ABslide, FitBall, and Conventionally Performed Trunk Curls. J. Athl. Train. 2004, 39, 37-43. 